\title{
"BOTA FÉ E DIGA LULA" O MELODRAMA COMO VIÉS INTERPRETATIVO DO JINGLE POLÍTICO
}

\section{Maria Izabel Muniz Ferrari ${ }^{1}$}

Resumo: O texto discute a importância do viés emocional, apresentado pelos dispositivos melodramáticos, como elemento relevante ao processo de decisão do voto. Parto da premissa de que a racionalidade, por si só, não dá conta de aspectos estéticos e linguísticos adquiridos pelas campanhas eleitorais na televisão. A análise da campanha de Lula, em 2002, permite a discussão da importância de matrizes do excesso na construção de um personagem político. Através da imaginação melodramática, o eleitor estabelece um elo emocional com o candidato, transformando o engajamento afetivo em engajamento político.

Palavras-chave: melodrama; campanhas eleitorais; jingles.

Resumen: El documento analiza la importancia de sesgo emocional, presentada por los dispositivos de melodramático, un aspecto importante para el proceso de votación decisión. Parto de la premisa de que la racionalidad por sí sola no puede hacer frente a la estética y lingüística adquirida por la campaña en la televisión. El análisis de la campaña de Lula en 2002, permite la discusión de la importancia de la matriz de exceso en la construcción de un personaje político. A través de la imaginación melodramática, el votante se establece un vínculo emocional con el candidato, haciendo el compromiso emocional en el compromiso político.

Palabras-clave: melodrama; campaña electoral; jingles.

Abstract: The paper discusses the importance of emotional bias, presented by the melodramatic devices, an important aspect to the process of voting decision. I start from the premise that rationality by itself can not deal with aesthetic and linguistic aspects acquired by the campaign on television. The analysis of Lula's campaign in 2002, allows discussion of the importance of mode of excess in the construction of a political character. Through the melodramatic imagination, the voter establishes an emotional bond with the candidate, turning the emotional engagement into political one.

Key-words: melodrama; election campaign; jingles.

\footnotetext{
${ }_{1}$ Mestranda do Programa de Pós-Graduação em Comunicação da Universidade Federal Fluminense. Pesquisadora da área de comunicação e mediações, com ênfase em Comunicação e Política. Graduada em Estudos Culturais e Mídia pela Universidade Federal Fluminense.
} 


\section{INTRODUÇÃO}

Áudio: "Que a estrela da esperança, do emprego e da mudança, mora do lado de cá”. O áudio foi destacado do jingle ${ }^{2}$ de campanha política do candidato Lula, exibido no $2^{\circ}$ turno, em 2002, cujo título é “Agora é Lula”. Embora a frase não faça nenhuma referência textual direta ao candidato, traz uma série de simbolizações sociais as quais o eleitor poderá se remeter para entender a mensagem. $\mathrm{O}$ apelo emocional, agregado ao processo, permite que o eleitor associe o texto à imagem de Lula (homem/candidato), independente de qualquer informação política detalhada sobre seus projetos de campanha.

Diante disso, o gênero melodramático pode ser analisado como viés interpretativo de aspectos emocionais presentes nos jingles. O melodrama ajuda a entender como se constrói um engajamento político através de aspectos emocionais trazidos à cena. Esses aspectos emocionais são estimulados a partir da interação da imagem e do som com o contexto social no qual o eleitor está inserido. Desta forma, o melodrama dá conta de explicar pontos ignorados pelas análises puramente racionais, uma vez que leva em conta o emocional, assim como os contextos individual e social dos envolvidos no processo de decisão de voto.

$\mathrm{O}$ artigo será desenvolvido com base em dois jingles usados na campanha de Lula, em 2002: o da pré-campanha, "Bota fé e diga Lula", e o do segundo turno, "Agora é Lula”. Cada jingle tem em média 2 minutos. Neles, as matrizes do melodrama funcionam como "arremate" do mosaico de símbolos e mensagens que compõem o jingle político. A não-linearidade do formato permite que sejam travados, quadro a quadro, processos de identificação simbólicos individuais e coletivos entre os diferentes grupos, representados no vídeo, e a realidade social em que vivem. Contudo, essa identificação não se estabelece sozinha, sendo o melodrama o elo que permite a significação dos símbolos expostos, pela imaginação melodramática.

O melodrama constitui uma chave de leitura pouco explorada nos estudos relativos ao comportamento político. Na ciência política, o processo de escolha do voto tem sido frequentemente explorado a partir do ponto de vista do comportamento racional. As teorias políticas que tomam como base a teoria econômica da racionalidade descartam a relevância do uso do melodrama na decisão do voto, assim como ignoram a personalidade individual do sujeito na escolha do candidato, bem como seus desejos, anseios e conhecimentos. Escolher um candidato pela sedução, pelo engajamento

\footnotetext{
2 Luiz Cláudio Lourenço (2009) descreve a trajetória dos jingles políticos no Brasil, apontando seu extensivo uso no rádio, entre os anos 30 e 6o, nas campanhas eleitorais de Getúlio Vargas e Jânio Quadros, por exemplo. Destaca que o formato continua sento prestigiado na cena política com o surgimento e popularização da televisão, em que adere um formato com linguagem de videoclipe.
} 
emocional, seria um ato irracional, pois seria o uso de um expediente político para um fim não político. "A função política das eleições numa democracia, presumimos, é selecionar um governo. Portanto, comportamento racional vinculado às eleições é comportamento orientado para esse fim e nenhum outro" (DOWNS, 1999, p. 29).

A preferência pelo racional no processo eleitoral expressa uma distinção cultural entre razão e emoção. Privilegiar a razão seria o mesmo que defender um ideal de objetividade, imparcialidade e informação, requerendo do eleitor/telespectador um entendimento crítico sobre o que é exibido. Já a emoção é associada a uma linguagem inferior (narrativa, enquanto "contação" de histórias), relegada a uma função muito mais de entreter, que de informar. Nesse contexto, o melodrama assume o papel fundamental de mediador de sentidos na comunicação política.

O modelo de sociedade construído no período Moderno vive mudanças, com a transição de crenças espirituais e rituais para valores morais. Neste contexto, a matriz melodramática do excesso ${ }^{3}$ dramatiza a vida das pessoas, tanto nas relações cotidianas, como na cena política. Sendo assim, o melodrama passa a ser entendido não só como um gênero, mas como uma visão de mundo, como uma "imaginação melodramática" (BROOKS, 1995, p. 2).

A decisão de estudar os jingles da campanha de Lula partiu da seguinte pergunta: o que mudou na produção do formato para a campanha do candidato que, em 2002, se tornou presidente? Depois de três tentativas anteriores $(1989,1994,1998)$, finalmente, Lula passa de operário, a líder mais popular do Brasil. O “Novo Lula”, eleito presidente do país, aprofundou o foco no candidato, em detrimento do partido, o fazendo de modo a ressaltar um discurso emocional com significativo potencial de identificação popular, em vez de um discurso mais argumentativo sobre de posições de esquerda. A história do candidato não mudou nesses últimos 13 anos, o que mudou foi sua forma de contá-la.

Os jingles, de forma específica, também sinalizam para essa mudança de foco da campanha, em que as escolhas no processo político deixam de se limitar ao formato racional, no qual o eleitor analisa de forma interpretativa e reflexiva as proposta do candidato, tomando sua decisão por aspectos quantitativamente previstos, passando a fazer uso de elementos musicais e visuais como fortalecedores de laços sociais. O som e a imagem não criam o cenário político, mas intensificam aspectos emocionais que motivam ações políticas.

O formato estético e linguístico dos jingles, com melodias simples e de fácil compreensão, acompanhados por vídeos com cortes rápidos, facilitam o entendimento

\footnotetext{
3 O excesso deve ser pensado como articulações da narrativa de maneira que seja possível mobilizar reações sensoriais e sentimentais. Além disso, representa o denominador comum em relação ao conceito de melodrama; liga o melodrama a uma matriz de narrativas populares das mais variadas ordens.
} 
e a retenção da mensagem por parte do eleitor. As experiências musical e visual assumem papel fundamental em detrimento do conhecimento prévio das propostas do candidato. Com isso, a imaginação melodramática preenche possíveis lacunas deixadas pela edição, funcionando como um arremate que une emoções individuais do eleitor e aspectos gerais relacionados ao candidato.

\section{A ESTÉTICA E LINGUAGEM DOS JINGLES}

O jingle enquanto peça publicitária ganha espaço no rádio brasileiro em 1932, período em que o governo autoriza propaganda no veículo. Antes disso, o formato já fazia muito sucesso nos Estados Unidos, onde foi criado. A simplicidade e o alcance de sua estética e linguagem logo são apropriados pela política como forma de comunicação, surgindo, então, o jingle político-eleitoral.

Não é preciso o período em que se inicia o uso dos jingles como ferramenta de campanha política. Antes mesmo do formato se firmar como peça publicitária nos EUA, no início dos anos 1920, já existiam as paródias musicais de cunho político, as quais satirizavam candidatos e políticos. Assim, acredita-se que o jingle político pode ter surgido antes mesmo do jingle comercial (LOURENÇO, 2009, p. 207). De certa forma, a música sempre esteve presente na publicidade e na comunicação políticas ${ }^{4}$. A relação da música com a política não é recente, mas o formato do jingle como peça publicitária ganhou força a partir dos anos 1930, com sua utilização por candidatos famosos, a exemplo de Getúlio Vargas e Jânio Quadros.

Vale destacar que o jingle dos anos 1930 é apenas uma peça musical, geralmente, com duração de 30 a 60 segundos, com letras fáceis e melodias simples. Neste formato fizeram sucesso os jingles "Varre, varre, vassourinha. Varre, varre, a bandalheira”, de Jânio Quadros (1960) e "Ai, ai, ai, Gêgê, de Getúlio Vargas (1930). O povo ainda espera por você”. Mais tarde, com a chegada e a popularização da televisão, é que são criados os jingles como os conhecemos hoje, com imagem e som sendo trabalhados em conjunto com a linguagem de videoclipe. $\mathrm{O}$ destaque dado às imagens na disputa política transforma as peças de campanha em grades de produções audiovisuais.

Reconhecer o potencial da música no jingle é o mesmo que reconhecer a importância das visões de mundo dos eleitores. Os efeitos musicais estão relacionados ao elo emocional estabelecido entre as pessoas e a política. A música tem efeitos

\footnotetext{
4 Conforme Lourenço (2009), "o uso político da música como condutor das emoções do público foi eficaz em 1789, durante a Revolução Francesa, quando o canto da Marseillaise serviu como grito de guerra para a tomada da Bastilha. O movimento nazista também fez um uso muito bem calculado da música em sua máquina de propaganda”.
} 
sinestésicos sobre o ouvinte, dos quais resultam as respostas emocionais. Esse feedback emocional se dá por três organizações musicais - ritmo, altura e melodia, as quais transmitem "sentimentos" ao público, sendo que este responde aos estímulos como exaltação emocional e simpatia (POLI, 2008).

A música é capaz de induzir afeto e permite construção de sentidos por parte dos sujeitos. No caso do uso da música em peça de campanha política, cabe observar o poder que o jingle ganha enquanto determinante na tomada de decisão do voto, uma vez que colabora na formação de impressões sobre o candidato, agindo na formação de julgamentos com base no estado de humor do eleitor. Este estado de humor, por sua vez, é alterado pela música e pelas significações individuais e coletivas estimuladas a partir dela. Diante disso, o melodrama ocuparia esse espaço de visão de mundo do eleitor, a partir do qual a música consegue manifestar seus efeitos emocionais:

\begin{abstract}
"A escala de tons determinada pelo artista atua de forma sinestésica na percepção, cooperando para uma resposta emocional à melodia. Através de estudos recentes, a emoção deixa de ser vista como algo irracional e assume um papel importante de função racional e determinante em todo o processo de escolha pessoal". (POLI, 2008, p. 231)
\end{abstract}

$\mathrm{O}$ efeito do jingle se potencializa com a imagem, que reitera a mensagem em alguns momentos, ou cria novos efeitos sobre o telespectador, potencializando o elo emocional com o candidato. Na campanha de Lula em 1989, o jingle "Lula lá lá”, muito lembrado, ainda hoje, pelo grande alcance que teve, era uma montagem simples, na qual um grupo de artistas agrupados cantava o jingle, com variações em closes na imagem pública dos artistas, na camisa do partido ou na bandeira do PT, com algumas outras variações de planos. Em 1989 também fez sucesso o jingle "Lá, lá, lá, Brizola”, do candidato à presidência Leonel Brizola.

De 1994 em diante, já se tem uma produção dos jingles com mais recursos de edição e montagem, como "Levanta a mão", de Fernando Henrique Cardoso (1994) e "Bota fé e diga Lula", da campanha em 2002. Neste mesmo ano, se tem uma grande variação de efeitos nos jingles de Lula, que variam desde planos até closes, big-closes, fusões de imagens e montagens. A linguagem de videoclipe nos jingles se aproxima do que é entendido por "vídeo promocional”.

“Criados na década de 70, apresentam efeitos especiais, um roteiro razoavelmente definido e uma tentativa de combinar imagens com as principais batidas da música, provocando variadas sensações sinestésicas". (HOLZBACH e NERCOLINI, 2009, p. 51) 
Uma segunda característica presente nos videoclipes, que também pode ser identificada nos jingles políticos, é o destaque à performance e à imagem musical do artista. No caso da campanha em análise, o artista é representado pela imagem do candidato Lula. Outras são trazidas como forma de representá-lo de forma indireta, sempre remarcando quem enuncia o discurso. A estética de videoclipe utilizada concede ritmo às imagens através de recursos inovadores de edição, com o intuito de que o espectador não consiga separar a música da imagem.

O tempo de duração de um jingle, em média, é de, aproximadamente, 3 minutos, podendo ser um pouco menor ou maior. Geralmente não apresentam narrativa linear, uma vez que a preocupação não está em contar uma história com início, meio e fim, mas sim em produzir apelos sensoriais, os quais devem ser revertidos em respostas emocionais, estas que, por sua vez, podem ser trabalhadas para o engajamento político do telespectador/eleitor. Do fato de não se tratar, necessariamente, de uma narrativa linear, ou seja, presa ao espaço e ao tempo, resulta que são possíveis diferentes formas de envolvimento e interpretação dos jingles, podendo variar de acordo com a visão de mundo de quem assiste, com o conhecimento prévio sobre o candidato, a consulta à memória de campanhas anteriores, aos anseios do eleitor e suas necessidades. A disposição afetiva é resgatada durante todo o jingle por meio de repetição de estrofes e refrões.

\subsection{PARADIGMA RACIONAL DE ANÁLISE DAS CAMPANHAS}

Na Ciência Política, o processo de escolha do voto tem sido frequentemente explorado a partir do ponto de vista do comportamento racional. As teorias políticas idealizam a racionalidade como única e melhor forma de o eleitor chegar à decisão do voto. Desta forma, o candidato deveria ser escolhido com base na análise crítica das propostas do candidato, com o objetivo de eleitor decidir seu voto com base em benefícios individuais ou coletivos.

Em oposição a essa racionalidade pura na política, outra linha de pesquisa sinaliza que limitar a decisão política à racionalidade seria aceitar a escolha do voto com base em baixas informações (POPKIN, 1994). O eleitor não é linear em seu processo de escolha do candidato, ele busca atalhos para sua avaliação. Diante disso, o melodrama poderia ser observado como atalho na campanha eleitoral.

Pensar o voto pelo olhar racional não quer dizer a defesa do voto como um ato em benefício do bem-estar de toda a nação. Pela teoria econômica da racionalidade, o ato de votar ganha papel de defesa de interesses sociais e econômicos, sejam esses individuais ou coletivos. "Essa linha de investigação rejeita peremptoriamente os 
componentes psicológicos das motivações individuais como fatores que explicariam o comportamento político eleitoral" (FIGUEIREDO, 1991, p. 69).

Algumas pesquisas já consideram o papel ativo de ambos os lados, eleitor e candidato, assim como identificam o papel persuasivo do discurso político no processo de decisão do voto (ALDÉ, DIAS e FIGUEIREDO, 1996, p. 3). Embora reconheçam a importância de crenças, valores morais, interesses e visões de mundo dos sujeitos, os coloca em um patamar inferior no processo. Há uma tentativa de prever as ações políticas dos candidatos, de forma a prever também as respostas possíveis do eleitor. Esse caráter previsível é que, segundo a visão da Ciência Política, agrega o teor de racionalidade ao processo de decisão do voto, sendo a imprevisibilidade emocional descredibilizada.

É comum ter o foco de pesquisa da comunicação política na tentativa de entender o processo comunicativo nas campanhas eleitorais pela interpretação do discurso - com isso, o foco se mantém no candidato e na sua estratégia de persuasão, não sendo consideradas as visões de mundo dos eleitores como determinantes ao processo de interpretação da campanha eleitoral. "Na disputa eleitoral por cargos majoritários ganha aquele que obtiver o maior número de votos, isto é, ganha quem conseguir persuadir a maioria” (ALDÉ, DIAS e FIGUEIREDO, 1996, p. 3). Creditar a interpretação da campanha eleitoral ao discurso do candidato volta ao problema de creditar o entendimento da propaganda política apenas à interpretação crítica, ou seja, se faz necessário um domínio intelectual e tecnológico para participação política efetiva, reforçando a situação de distinção.

A escolha dos jingles como objeto de análise dialoga diretamente com a questão "racional" do domínio da tecnologia da escrita como determinante do entendimento da mensagem. O fato de o eleitor não ter domínio da tecnologia não o impede de significar o que assiste, e, assim, interpretar a campanha eleitoral. O discurso tem papel e valor dentro do processo, mas a significação e a interpretação do mesmo não se dão nesse âmbito discursivo, mas, sim, na esfera social, ou seja, é contextualizado à realidade do eleitor interpretante, o qual decodifica a mensagem levando em conta aspectos econômicos, sociais e até mesmo emocionais.

As relações sociais são muito complexas para serem pensadas apenas pela tecnologia, elas devem ser levadas em conta também, assim como questões culturais, econômicas e aspectos interativos. A tecnologia sozinha não determina o meio, o uso que fazemos delas é que deve ser levado em conta (WILLIAMS, 1988). O processo de identificação, comoção e engajamento afetivo também são relevantes à decisão do voto e não se dão no âmbito da cultura letrada, mas sim no campo das emoções. Diante disso, o gênero melodramático como chave de leitura da campanha eleitoral propicia 
um olhar sobre os jingles que dá conta de aspectos sinestésicos, os quais resultam em respostas emocionais do eleitor.

Mesmo quando o jingle é apenas musical, já possui efeitos subliminares importantes sobre o ouvinte. "A linguagem sonora no meio radiofônico desenvolve uma caracterização composta por: emocionalidade, fala reiterativa, conversa fixadora e imagem marca" (NUNES, 2004). A síntese desses elementos reflete a imagem criada do candidato. Esta imagem, somada à linguagem emocional, faz com que o leitor interprete o jingle para formar um conceito sobre a candidatura.

\subsection{O MELODRAMA COMO OLHAR INTERPRETATIVO}

A principal questão do trabalho se baseia na utilização do melodrama como chave interpretativa de aspectos emocionais não explicáveis pelas teorias políticas da racionalidade. O jingle político funciona como arremate da campanha eleitoral, uma vez que, através da imaginação melodramática - construída socialmente, pela mídia e pelos programas eleitorais - cria engajamento político entre eleitor e candidato, por meio de engajamento emocional. O formato audiovisual que agrega música e imagem, desperta emoções individuais, independentes do contexto político, assim como coletivas, atreladas ao momento da eleição.

$\mathrm{Na}$ modernidade, as crenças espirituais e os rituais começam a ser gradativamente substituídos por valores morais, difundidos pela pedagogia moralizante, que, no caso do melodrama, se utiliza da matriz melodramática do excesso para dramatizar a vida das pessoas.

“(...) Melodrama é, portanto, normalmente, não apenas um drama moralista, mas o drama da moralidade; ele luta para encontrar, articular, demonstrar, provar a existência de uma instância moral que, embora colocada em questão, mascarada pela vilania e pelas perversões de julgamento, existe e pode se fazer uma força presente e categórica entre os homens". (BROOKS, 1995,2)

Na disputa política, o melodrama não é uma ferramenta estrategicamente aplicável ao Horário Gratuito de Propaganda Eleitoral (HGPE), de forma a obter resultados previsíveis. O uso das categorias do excesso pode ser compreendido como eficaz para um processo de engajamento afetivo com o candidato, o que resultaria em engajamento político posterior. Dessa forma, o gênero melodramático se manifesta como olhar interpretativo sobre as campanhas. Isso só faz sentido perante uma imaginação melodramática compartilhada entre os eleitores.

Assim como as demais categorias artísticas e sociais, a política se utiliza da estética melodramática, seja nos discursos orais dos séculos passados ou nas 
megaproduções audiovisuais de hoje. Há intenção de fazer representar as classes ou o poder em troca do engajamento. Para isso, a política mantém o rótulo de racionalidade absoluta sobre as decisões no meio, mesmo sendo um universo carregado de sentidos, alternando-se entre momentos de legitimação da racionalidade, e outros de construção de espaços de representação.

A complexidade do campo da comunicação política o leva, em alguns recortes teóricos, a uma aproximação com as ciências que tentam dar conta do imagético do eleitor, como a psicologia política. Essa linha de estudo tenta interpretar a relação do HGPE com o processo pelo qual as pessoas fazem sentido no mundo da política ${ }^{5}$. A experiência de acompanhar um candidato por comícios, programas de rádio e contatos interpessoais, se modifica completamente quando a disputa passa para a esfera televisiva. Partindo da estética e da linguagem expressiva da televisão, é possível estabelecer um olhar sobre as campanhas eleitorais a partir do gênero melodramático.

O reconhecimento do melodrama como gênero narrativo o valida como modo de "percepção de mundo" (BALTAR, 2006). No HGPE essa visão instaurada pela modernidade é difundida por uma pedagogia moralizante das sensações, manifestada em discursos cada vez mais próximos de temáticas cotidianas, os quais trazem as instâncias da intimidade à tela de forma a criar elo emotivo entre candidato e eleitor. Neste contexto, a vida cotidiana passa a ser trazida a público não só pelas páginas dos jornais; as pessoas buscam aconselhamento moral também nos produtos audiovisuais (SCHUDSON, 1978).

\section{O MELODRAMA NA POLÍTICA}

No modelo eleitoral brasileiro, o qual dá grande destaque à campanha pela televisão, o melodrama pode, em alguns usos, ser comparado ao que observamos em telenovela, filmes ou demais produtos audiovisuais. Um dos elementos que aproxima a campanha na TV de uma telenovela, por exemplo, é a construção em capítulos, em que se estrutura com base em temas de interesse e reconhecimento público, gerando no diaa-dia elo emocional entre quem fala e quem assiste.

No HGPE, a vida privada de Lula foi trazida como exemplo moralizante, narrando-se muito de sua trajetória pessoal, a fim de reforçar a sua consagração pública. Cria-se, assim, modelo moral de bondade, de luta, de esperança etc. Por meio da privacidade, cria-se intimidade com o telespectador, fator que estimula a confiança,

5 Os mídias passam a ser vistos não mais como condutores neutro de informação, mas sim como instituições que contribuem para dar significado e interpretar eventos e temas políticos (PORTO, 1999). 
fazendo com que se possa criar identificação com o Lula candidato, alcançando o engajamento pelo seu discurso, como nos trechos abaixo.

\begin{abstract}
"Nesse programa eleitoral a figura principal não é o candidato, a figura principal é você." - (HGPE - 1989, Lula - Rede Povo)

"Toda vez que venho a Caetés me dá um sentimento muito forte, porque hoje eu tenho mais clareza do que foi a vida da minha mãe e nossa quando a gente era pequeno aqui em Caetés. Eu sou o caçula dos homens, minha mãe teve oito filhos. Minha mãe se chamava Eurides Ferreira de Melo, mas a gente sempre tratava ela como Euri. O meu pai chamava Aristides da Silva, meu pai foi embora para São Paulo. Nesse tempo eu tinha um TL, era chic ter um TL, torneiro mecânico naquela época podia comprar um TL (...)”. - (HGPE - 2002, Lula Origem Social)
\end{abstract}

Os fragmentos citados se referem as duas campanhas eleitorais, separadas por mais de uma década: a primeira, em 1989, e a segunda, em 2002. O principal a observar é que, em ambas as campanhas, a espetacularização do eu, o foco nas emoções dos personagens envolvidos, suas necessidades e desejos, seja do candidato ou do eleitor, estão em destaque, seja pelo discurso direto, seja em forma de representação. Contudo, no ano de 2002, também pode ser observado maior investimento moral na figura de Lula, com mais ênfase ao uso do melodrama.

A matriz de excesso é uma ferramenta eficaz na construção dessas narrativas. Nessa construção da imagem pública de Lula vêem-se alguns elementos sensacionalistas, os quais determinam o modo de excesso da narrativa. Algumas dessas características indicadas podem ser encontradas nos jingles políticos, como, por exemplo, uso de marcas da oralidade, muito fortes no discurso de Lula, o qual possui muitos erros de português e linguagem simples, alcançando o público que o interessa; presença de marcas sensoriais, perceptíveis com o uso do primeiro plano, havendo uma alternação entre primeiro plano e close em algumas falas de muita comoção, como quando fala da família; uso de imagem fotográfica em sequência cronológica, para que se propicie engajamento emotivo de quem assiste (ENNE, 2007).

Outro recurso trabalhado na campanha de Lula é a construção de um herói, que sobreviveu às dificuldades na vida pessoal e aos julgamentos na vida política - vide a forma como saiu sem arranhões das acusações sobre o mensalão. É interessante observar como a esfera personalista de 2002 passa as acusações para a imagem do partido, mantendo Lula ileso.

Essa relação com o candidato pode ser comparada à relação que os súditos tinham com o rei no regime monárquico, em que o soberano teria dois corpos: um corpo humano, que nasce, vive, adoece, envelhece e morre, e um corpo político místico, perene e imortal. "O rei, pela graça de Deus é a imitação de Jesus Cristo, por isso possui duas naturezas: a humana, mortal e a mística ou divina, imortal". (KANTOROWICZ, 1998) 
Esse processo de reconhecimento dos personagens como heróis ou vilões se dá por meio de uma "moral oculta" presente na "imaginação melodramática" do eleitor. A eficácia do processo de 'melodramatização' da política pode ser vista pela manutenção do formato das campanhas produzidas para televisão, com mudança superficial do personagem e manutenção da estratégia. Com isso, é cada vez mais crescente a gama de profissionais especializados na produção de propaganda para TV, com estratégias semelhantes às das propagandas comerciais, em que as sensações e os desejos são motivados, não para compra monetária, mas para escolha pelo engajamento ou identificação com o personagem/candidato.

A campanha eleitoral não é classificada como gênero melodramático, mas traz a matriz do excesso e as categorias de análise do gênero. "O excesso liga o melodrama a uma matriz de narrativas populares das mais variadas ordens - desde os espetáculos de feira e de pantomima, até as literaturas de cordel e folhetim” (BALTAR, 2006, p. 5).

\subsection{OS JINGLES DE 2002: “AGORA É LULA" E "BOTA FÉ E DIGA LULA"}

A escolha da campanha à presidência de 2002, do então presidente da República, Luis Inácio Lula da Silva, se deu ao fato de ter sido montada a partir da imagem do "homem Lula", não do candidato Lula, sendo fortemente trabalhados aspectos emocionais, os quais culminaram em engajamento político suficiente à eleição e à posterior reeleição do mesmo.

O candidato esteve na disputa em 1989, 1992, 1994 e 1998, sendo derrotado em todas elas. O Lula apresentado nas diferentes campanhas não teve sua história de vida alterada, mas a forma como ela foi contada na campanha eleitoral é que mudou no ano de 2002. A própria campanha trouxe o slogan "Novo Lula" em seus programas, em que a ideia do Lula "homem" (sua intimidade e história de vida) foi explorada de forma a atingir o emocional do eleitorado.

Para análise foram escolhidos dois Jingles de campanha: "Agora é Lula" e "Bota Fé e Diga Lula", ambos de 2002. O primeiro tem 1 minuto e 20 segundos de duração e o segundo 2 minutos e 7 segundos. Como metodologia foram transcritos todos os jingles, sendo consideradas músicas e imagens como relevantes. Para discussão dos conceitos, e como forma de analisar o material, foram criadas três categorias de classificação das imagens: imagens que se repetem nos jingles; imagens que remetem indiretamente à política (Lula/PT) e imagens que remetem diretamente ao candidato Lula ou ao Partido dos Trabalhadores (PT). 
A primeira categoria, imagens que se repetem nos jingles, dá conta de uma série de imagens gerais presentes nos dois jingles, mas não só neles, como, também, nos programas de campanha. Imagens gerais são aquelas que possuem diferentes possibilidades de significados, sendo todos compartilhados pelo imaginário social. A imagem da bandeira nacional, por exemplo, aparece nos dois jingles e pode ser interpretada de diferentes formas por quem assiste. Pode vir representando apenas que se trata de uma eleição majoritária, para escolha de um presidente que irá governar o país; assim como também permite uma leitura direta à ideia de povo representado, sendo o presidente Lula modelo de liderança; de acordo com a melodia, pode representar, ainda, esperança de um Brasil melhor. A relação entre imagem, som e significados não é dada somente pela narrativa, mas sim construída, levando-se em conta "imaginação melodramática" dos sujeitos.

A segunda categoria criada foi a de imagens que remetem indiretamente à política, significadas pelo contexto intra ou extra jingle. $\mathrm{O}$ fato de serem necessários elementos extra jingle para interpretação das imagens reforça a teoria de que o jingle age além da simples repetição do nome do candidato, de seu número ou da legenda. $\mathrm{O}$ jingle ganha sentido político a partir de sua interpretação, com a ajuda do melodrama, pelas categorias do excesso.

No caso do jingle "Agora é Lula”, um exemplo marcante é o uso da imagem de estrelas. Durante o vídeo são usadas diferentes imagens de estrelas, no céu, de madeira, de plástico, tecido, dentre outras. Quem acompanha a trajetória política do partido sabe que o PT é representado pelo símbolo da estrela, criando o link entre a imagem e a política; mas isso não é uma regra, principalmente em campanha na qual o elo foi fortalecido pela história de vida do candidato e pela percepção de mundo do eleitor, deixando a imagem do partido em segundo plano. Se deslocada do jingle político, uma estrela no céu pode adquirir inúmeros outros significados, como a simples chegada do anoitecer; no entanto, quando inserida em uma peça política, as possibilidades de interpretação se ampliam através da interpretação baseada no conhecimento do eleitor, nas identificações que estabelece e nas suas experiências individuais e coletivas.

A imagem de homens com macacão em uma fábrica, por exemplo, são cenas que se repetem nos dois jingles. Fora da cena eleitoral pode significar um grupo de trabalhadores empregados, desempregados ou mesmo o símbolo de uma área profissional. $\mathrm{O}$ fato de as imagens estarem recortadas no jingle, as agrega, indiretamente, sentido de emprego como proposta de campanha e, mais do que isso, faz referência direta ao candidato Lula, que teve uma história trabalhista como operário, possibilitando identificação por parte do eleitor. 
No jingle "Bota fé e diga Lula", a imagem de tecidos nas cores vermelha e branca também ganha sentido pelo fato de o jingle tratar de uma peça política - fora desse contexto poderia adquirir outros significados. Isso reforça a necessidade de uma “imaginação melodramática” para leitura dos jingles. Nesse caso, o formato audiovisual favorece no processo de significação da mensagem através de apelos emocionais. Esse link entre as cores e o partido político e, por sua vez, ao candidato Lula, se dá no processo de significação pela memória do eleitor, que sabe as cores do partido previamente, e cria a rede de relações entre os objetos e a utilização política deles no jingle. Um mesmo tecido vermelho, em algum outro contexto, pode adquirir significado completamente diferente.

A terceira categoria criada foi a de imagens que remetem diretamente ao candidato. Essa terceira e última categoria se resume a apenas duas imagens presentes nos jingles, do candidato Lula e da bandeira do PT. Simplificar o jingle à imagem de Lula e da bandeira do PT como única forma de relação com o candidato é ignorar um universo de significações possíveis que possuem efeitos significativos sobre a decisão do voto. Os dois jingles apresentam narrativas não-lineares, em que imagens e música (letra) não têm relação direta entre si. Também não é apresentada uma temática predominante. São tratados temas diversos como família, fome, educação e juventude.

Na pré-campanha foi trabalhado o jingle "Bota fé e diga Lula". O jingle apresenta letra simples e melodia que alterna entre o gênero musical do forró e um hino de torcida. As duas opções musicais também se mostram coerentes com a imagem popular apresentada pelo candidato. O jingle político atua em uma eleição com o princípio de construir as relações interpessoais, podendo mobilizar um grande número de pessoas a favor de uma ideia. A sinestesia age no sujeito a partir de um estímulo auditivo, reagindo emocionalmente no indivíduo, e levando-o a ação (POLI, 2008, p. 232).

\subsection{O GÊNERO MELODRAMÁTICO NOS JINGLES}

A matriz melodramática do excesso dramatiza a vida das pessoas, tanto nas relações cotidianas, quanto na cena política. Sendo assim, o melodrama passa a ser entendido não só como um gênero, mas também como uma visão de mundo, como uma "imaginação melodramática”6 (BROOKS, 1995, p. 2). Desta forma, o eleitor interpreta as campanhas eleitorais a partir de uma leitura moralizada proporcionada pelo

\footnotetext{
${ }^{6}$ No século XX, o melodrama vai deixando de ser apenas um gênero e passa a atuar na imaginação social, imaginação melodramática, que seria uma visão de mundo. Esse modo de ver o mundo parte de uma lente permeada de valores sociais moralizantes, em que aspectos intimistas são trazidos para cena no âmbito sensível, deixando que o privado invada o público sem constrangimentos.
} 
melodrama, ou seja, a racionalidade não dá conta de aspectos emocionais, pessoais e específicos de cada contexto em que está inserido o eleitor. Nos jingles políticos, essa visão de mundo instaurada pela modernidade é difundida por uma pedagogia moralizante das sensações, manifestada em discursos cada vez mais próximos de temáticas cotidianas, os quais trazem as instâncias da intimidade à tela, de forma a criar elo emotivo entre candidato e eleitor. "Antes de ser um meio de propaganda, o melodrama será o espelho de uma consciência coletiva” (BARBERO, 2003, p. 170).

As matrizes do melodrama são identificáveis nos dois jingles, sendo possível observar as três categorias do excesso: obviedade, simbolização exacerbada e antecipação. Em todo o jingle é perceptível o uso da reiteração, em que a imagem do Lula, a letra da música, a melodia, o primeiro plano, os closes escolhidos e o cenário tangenciam para a narrativa, de forma a reiterá-la - com isso, vai-se construindo e reafirmando engajamento afetivo com o personagem.

A obviedade é mais uma categoria do excesso presente nos jingles. $\mathrm{O}$ uso da obviedade se dá frente ao olhar de julgamento público, possibilitado pela "moral oculta” presente no gênero melodramático. O olhar do eleitor enquanto olhar público precisar ser personificado, sendo então incorporado ao personagem político. Para o uso da obviedade, melodia, letra e imagem precisam convergir para um mesmo olhar de apreciação. "O uso da reiteração óbvia funciona para compelir o espectador a reagir em favor do herói da história" (BALTAR, 2006, p. 6).

No jingle "Bota fé e diga Lula" se percebe o uso da obviedade no verso "a favor de um povo pobre, mas nobre e trabalhador". Esse verso tem efeito a partir do julgamento de valor do candidato Lula como sendo de origem pobre e trabalhadora, criando identificação emocional entre a história de vida do candidato e a do personagem do jingle, que representava grande parte do povo brasileiro.

Já a antecipação, é uma categoria que reforça o lugar da comoção pela construção de excitação emocional. Um exemplo de antecipação, no caso dos jingles, são os versos e as imagens que se relacionam com o futuro e com a vitória do candidato. Nos dois videoclipes estão presentes imagens de torcidas comemorando, possibilitando, por antecipação, a significação de comemoração da vitória do candidato, que, por sua vez, representa ali a vitória da nação.

\section{CONCLUSÃo}

Essa pesquisa buscou iniciar análise em que o melodrama representa uma chave de leitura das campanhas eleitorais, dando conta de aspectos emocionais ignorados pelas análises racionais. Para isso, o melodrama não coloca as emoções dos 
eleitores como dispositivo de manipulação de suas decisões, mas sim como recurso interpretativo da mensagem política. Isso implica, em certa medida, na democratização da política, uma vez que a leitura racional pautada em "letramento" distintivo divide lugar com leitura pautada em emoções, na 'imaginação melodramática’ do eleitor.

No caso dos jingles, pôde-se observar que essa possibilidade de interpretação pelas matrizes do melodrama se intensifica com a utilização da estética e da linguagem de videoclipe, propiciando ampliação de propagação da mensagem, assim como ampliando as possibilidades de significações estabelecidas. Assim, leituras antes vistas como irracionais, por levarem em conta aspectos emocionais, agora são tidas como válidas no processo de decisão do voto, uma vez que representam a visão de mundo do eleitor, que não pode ser ignorada no processo.

O estudo questiona a distinção cultural entre razão e emoção. A interpretação do jingle político pelas categorias do excesso não invalida seu potencial reflexivo. $O$ olhar melodramático sobre as campanhas simplifica e amplifica o processo de decisão do voto, relegando ao âmbito das imagens o que, antes, era privilégio de uma oralidade de entendimento restrito. $\mathrm{O}$ gênero melodramático pôde ser observado nos jingles em análise como elemento colaborativo para compreender o processo que naturaliza a superexposição da intimidade dos candidatos nas campanhas contemporâneas. Com isso, os jingles são estruturados de forma a alcançar a identificação e a comoção do público, duas variáveis motivadas pelo excesso, e invalidadas como elemento político pelas teorias da racionalidade.

\section{BIBLIOGRAFIA}

ABREU, Maurício de A. Evolução Urbana do Rio de Janeiro. Rio de Janeiro. IPLANRIO/Zahar Editora, 1987.

ALBUQUERQUE, Afonso de. Aqui você vê a verdade na tevê: a propaganda política na televisão. Niterói: Universidade Federal Fluminense. Mestrado em Comunicação, Imagem e Informação (MCII), 1999.

ALBUQUERQUE, Afonso de. Advertising ou propaganda? O audiovisual político brasileiro numa perspectiva comparativa. Artigo apresentado na XIII Compos, São Bernardo do Campo, São Paulo, 2004.

ALDÉ, Alessandra; DIAS, Heloisa; FIGUEIREDO, Marcus e JORGE, Vladimyr J. Estratégias de Persuasão em Eleições Majoritárias: Uma Proposta Metodológica para o Estudo da Propaganda Eleitoral. in : Figueiredo, Rubens (Org.), Marketing Político e Persuasão Eleitoral, São Paulo, Fundação Konrad Adenauer, 2000.

BALTAR, Mariana. Moral Deslizante - releituras da matriz melodramática em três movimentos. Artigo apresentado na XV Encontro da Compós, na Udesp, Bauru, SP, 2006. 
BALTAR, Mariana. Realidade lacrimosa - diálogos entre o universo do documentário e a imaginação melodramática. Tese de Doutorado em Comunicação Social. Niterói, Programa de Pós-Graduação em Comunicação da Universidade Federal Fluminense, 2007.

BARBERO, Jesus Martin. Dos Meios às Mediações: comunicação, cultura e hegemonia. Rio de Janeiro, Editora UFRJ, 2003. $2^{\text {a }}$ Edição.

BARREIRA, Irlys. Chuva de Prata: ritos e símbolos de campanhas eleitorais no Brasil. Rio de Janeiro, Relume Dumará, 1998.

BROOKS, Peter. The Melodramatic Imagination Balzac, Henry James, melodrama and the Mode of Excess. Yale, Yale University Press, 1995. (Edição Original 1976)

DOWNS, Anthony. Uma Teoria Política da Democracia. São Paulo, Edusp, 1999.

ENNE, Ana Lúcia. O Sensacionalismo como Processo Cultural. In: Revista ECO-PÓS. Revista do Programa de Pós-Graduação em Comunicação e Cultura da Escola de Comunicação, Rio de Janeiro, Universidade Federal do Rio de Janeiro, v.10, n.2, 2007, pp. 70-84.

FIGUEIREDO, Marcus. A Decisão do Voto - Democracia e Racionalidade. São Paulo: Editora Sumaré: ANPOCS, 1991.

GOMES, Wilson. Transformações da política na era da comunicação de massa. São Paulo, Paulus, 2004.

HOLZBACH, Ariane Diniz e NERCOLINI, Marildo. Videoclipe em tempos de reconfigurações. Artigo publicado na Revista FAMECOS, Porto Alegre, $n^{0} 39$, Agosto de 2009.

JORGE, Vladimyr Lombardo. Os Meios de Comunicação de Massa nas Campanhas Eleitorais. Dissertação de Mestrado defendida pelo autor em 1995, no Instituto Universitário de Pesquisas do Rio de Janeiro (Iuperj).

KANTOROWICZ, Ernst. Os dois corpos do rei: um estudo sobre teologia política medieval. São Paulo: Companhia das Letras, 1998.

LOURENÇO, Luiz Cláudio. Jingles Políticos: estratégia, cultura e memória nas eleições brasileiras. Artigo publicado na edição $\mathrm{n}^{0}$ 4, da Revista Aurora, da Universidade Católica de São Paulo, 2009.

NORRIS, Pippa. A Virtuous Circle. Political Communications in Postindustrial Societies. Cambridge, Cambridge University Press, 2000.

NUNES, Márcia Vidal. O rádio no horário eleitoral de 2002: a sedução sonora como estratégia de marketing. Artigo apresentado no IV Encontro de Núcleos de Pesquisa do Intercom, 2004.

ONG, Walter J. Oralidade e Cultura Escrita. São Paulo: Papirus, 1998.

POLI, Silvia Thaís de. A função sinestésica da música no jingle político. Artigo publicado na Revista Ciência \& Cognição, vol.13, julho de 2008. 
POPKIN, Samuel L. The Reasoning Voter: Communication and Persuasion in Presidencial Campaigns. Chicago, 1994. $2^{a}$ Edição.

PORTO, Mauro P. Interpretando o Mundo da Política: Perspectivas Teóricas no Estudo da Relação entre Psicologia, Poder e Televisão. In: Artigo apresentado na XXIII Encontro Anual da Associação Nacional de Pós-Graduação e Pesquisa em Ciências Sociais (ANPOCS). Minas Gerais, 1999.

SCHUDSON, Michael. Discovering the news: a social history of American newspaper. [USA]: Basic Books [c1978]. 228. Cap. 3: Stories and information: two journalism in the 1890 s, p. 88-120. Traduzido para o português. Ver. Técn de A. de Albuquerque.

SENNET, Richard. O Declínio do Homem Público: As Tiranias da Intimidade. Tradução Lygia Araújo Watanabe. São Paulo, Companhia das Letras, 1988.

STEIBEL, Fabro. Judicialização da política e propaganada partidária: a visão do judiciário sobre as campanhas presidenciais de 2002. Artigo publicado na UniRevista, vol. 1, $\mathrm{n}^{\mathrm{0}} 3$, Julho de 2006.

THOMASSEAU, Jean-Marie. O Melodrama. São Paulo, Perspectiva, 2005.

VINCENT-BUFFAULT, Anne. História das Lágrimas - Séculos XVIII-XIX. Rio de Janeiro, Paz e Terra, 1988. 